\title{
Estimativas e projeções populacionais para pequenos domínios: uma avaliação da precisão para municípios do Rio de Janeiro em 2000 e 2007
}

\author{
Luana Paula Gentil de Brito* \\ Suzana Cavenaghi** \\ Paulo de Martino Jannuzzi ${ }^{\star \star \star}$
}

\begin{abstract}
As projeções populacionais vêm sendo utilizadas, com frequência cada vez maior, como subsídio para planejar o desenvolvimento econômico, social, político e ambiental de diversos países. Entretanto, quanto maiores os níveis de detalhamento geográfico, demográfico e temporal requeridos, menos precisas se tornam as projeções. Em pequenos domínios, como municípios, por exemplo, enfrentam-se dificuldades como tamanho reduzido da população, volatilidade dos dados nos seus padrões de crescimento, falta de informações de qualidade, entre outros. O objetivo deste trabalho é avaliar algumas metodologias de projeções populacionais para pequenos domínios, tomando como objeto de estudo os municípios do Estado do Rio de Janeiro. As técnicas estudadas são os métodos AiBi, relação de coortes de Duchesne e correlação de razões, usadas para comparação com os resultados do Censo 2000 e com a Contagem de 2007. Os resultados comparativos com o Censo 2000 indicam que, em média, as estimativas e projeções provenientes da aplicação dos três métodos apresentam um nível de precisão dentro de uma margem aceitável, mas os erros variam de $-21,4 \%$ a $24,1 \%$ e as projeções tendem a ser subestimadas. Já a comparação dos resultados com a Contagem de 2007 revelou-se menos precisa. Pelos motivos descritos neste trabalho, o método de correlação de razões, que utiliza variáveis sintomáticas, mostrou melhores resultados do que os demais, entre o conjunto de métodos avaliados para os municípios do Rio de Janeiro.
\end{abstract}

Palavras-chave: Projeções populacionais. Pequenos domínios. Estimativas de precisão. Rio de Janeiro.

\section{Introdução}

Suprir as necessidades básicas de uma população requer, entre outras ações, a formulação de planos e programas sociais que, para serem implementados de maneira adequada, precisam, no mínimo, se basear em uma previsão do tamanho e da composição etária desta população. Por este motivo, a projeção populacional tem se tornado uma técnica demográfica cada vez mais imprescindível para planejar o desenvolvimento

\footnotetext{
* Mestre em Estudos Populacionais e Pesquisas Sociais, Escola Nacional de Ciências Estatísticas, do Instituto Brasileiro de Geografia e Estatística (Ence/IBGE).

** Doutora em Demografia, professora e pesquisadora da Escola Nacional de Ciências Estatísticas, do Instituto Brasileiro de Geografia e Estatística (Ence/IBGE).

*** Doutor em Demografia, assessor técnico da Diretoria Executiva da Fundação Seade, professor e pesquisador da Escola Nacional de Ciências Estatísticas, do Instituto Brasileiro de Geografia e Estatística (Ence/IBGE).
} 
econômico, social, político e ambiental de uma nação (NAÇÕES UNIDAS, 1978).

As projeções populacionais, para o setor público, auxiliam no conhecimento e quantificação de demandas futuras de diversas naturezas, tais como estradas, escolas, hospitais, áreas de lazer, etc., e, para o setor privado, servem para estimar o tamanho potencial de seu "mercado" futuro (PRESTON et al., 2001).

Os programas e as ações, tanto do setor público quanto do privado, subsidiadas por projeções populacionais envolvem custos. A adequada aplicação destes recursos depende da qualidade das projeções utilizadas, que devem estar mais próximas da realidade para que não haja desperdício de investimentos. Uma projeção, se muito distante do real, pode causar gastos desnecessários ou deixar de atender a uma parcela necessitada da população. No caso de investimentos do setor público, principalmente, a alocação correta de recursos pode significar o atendimento de grupos populacionais que ficariam fora do alcance das ações públicas. No entanto, obter projeções totalmente corretas é muito difícil, se não impossível em pequenos domínios. Por este motivo, a avaliação de projeções populacionais se torna uma ferramenta importante para identificar os erros de cada método e selecionar aquele que minimiza estes erros, sempre considerando os contextos específicos da população projetada, os dados disponíveis, assim como o período necessário para a projeção.

O Método das Componentes, que incorpora tendências futuras do comportamento da fecundidade, mortalidade e migração, fornece projeções populacionais segundo sexo e grupos de idade (NAÇÕES UNIDAS, 1978). No entanto, sua aplicação não constitui uma tarefa fácil, pois, para estabelecer hipóteses a respeito do futuro das três componentes demográficas, são necessárias informações estatísticas de qualidade e, quanto menor o tamanho da população, mais difícil a obtenção de dados confiáveis, devido, principalmente, à varia- bilidade ao acaso a que estão sujeitos os pequenos domínios. Assim, o Método das Componentes não pode ser aplicado em qualquer tipo de população. Por esta razão, alguns métodos têm sido sugeridos como alternativa para projeções populacionais em domínios menores. ${ }^{1}$

Algumas iniciativas importantes para gerar projeções com maior nível de detalhamento geográfico e demográfico - pelo Método das Componentes (em nível estadual) e métodos alternativos para obter estimativas municipais - vêm sendo desenvolvidas há muitos anos por instituições estaduais como a Fundação Sistema Estadual de Análises de Dados (Seade - São Paulo), a Fundação de Estatística e Economia (FEE - Rio Grande do Sul), o Instituto Paranaense de Desenvolvimento Econômico e Social (Ipardes - Paraná) e a Superintendência de Estudos Econômicos e Sociais da Bahia (1999). No entanto, esta atividade ainda não foi adotada em estados com potencial para tanto, ou seja, com boa cobertura de estatísticas vitais e disponibilidade de pessoal técnico, como, por exemplo, o Rio de Janeiro.

Assim, o objetivo deste trabalho é avaliar algumas metodologias de projeções populacionais para pequenos domínios, que são regularmente utilizadas no Brasil, tomando como objeto de estudo os municípios do Estado do Rio de Janeiro. As técnicas aqui estudadas são os métodos $\mathrm{AiBi}$, relação de coortes de Duchesne e correlação de razões, usadas para comparação com os resultados do Censo 2000 e a Contagem de 2007.

Mais recentemente, outras técnicas de projeção e estimação demográfica têm sido propostas na literatura acadêmica - nacional e internacional -, tais como aquela apresentada por Jannuzzi (2007), que utiliza dados de registros administrativos em um sistema de equações diferenciais combinados com opiniões de especialistas sobre as tendências demográficas, e várias outras discutidas em Rao (2003). Como bem observa Rao (2003), a demanda por estatísticas para pequenos domínios tem levado à proposi-

\footnotetext{
${ }^{1}$ Nas projeções oficiais para o Brasil em níveis estaduais e municipais, realizadas pelo IBGE, é aplicado um método matemático, com o qual somente é possível obter projeções para o total da população em estudo.
} 
ção de novos modelos de estimação, em substituição às técnicas mais tradicionais como as aqui tratadas. Tais modelos, com diferentes níveis de sofisticação e pressupostos, valem-se de registros administrativos relacionados à dinâmica populacional - correntemente compilados - e, de forma crescente, de dados primários amostrais, levantados para domínios mais amplos, de forma periódica.

A melhoria da qualidade de registro e de cobertura dos cadastros públicos, as reformulações que se anunciam para os próximos anos no Sistema de Pesquisas Domiciliares pelo IBGE e os avanços em termos de geocodificação dos dados do Censo Demográfico 2010 certamente criam boas perspectivas, a curto e médio prazos, para aplicação de modelos mais sofisticados para produção de estimativas populacionais mais precisas no Brasil. Entretanto, os métodos atualmente em uso para estatísticas oficiais ainda são aqueles mais tradicionais, os quais serão avaliados neste texto.

O artigo está estruturado em três seções. Inicialmente, são abordados os critérios de avaliação de projeções populacionais, em seguida, apresentam-se as três técnicas aqui empregadas e as fontes de dados utilizadas e, por fim, discutem-se os resultados entre as técnicas e as estimativas oficiais do Censo e da Contagem, procurando identificar os diversos fatores explicativos para as diferenças encontradas.

\section{Metodologia}

\section{Critérios para avaliação e elaboração de projeções populacionais}

Tendo em vista que as projeções para áreas mais desagregadas são afetadas por problemas de disponibilidade e confiabilidade de dados, pela grande influência da migração, pelo impacto de eventos especiais e por circunstâncias únicas de crescimento populacional, seus resultados são questionados quanto à confiabilidade. Por isso, é importante a avaliação de todo o processo de elaboração de uma projeção populacional, especialmente para os domínios menores. Os critérios que podem ser tomados para avaliação são muitos e todos importantes para considerar um resultado como mais ou menos confiável.

Smith et al. (2001) definiram alguns critérios que julgam ser mais relevantes para avaliação e seleção de método de projeções populacionais: precisão; nível de detalhes necessários; validade; plausibilidade; custos de produção; conveniência; facilidade de aplicação e explicação; utilidade como ferramenta analítica; e aceitação política. Os dois primeiros critérios foram utilizados no processo de elaboração e avaliação das projeções populacionais dos municípios do Rio de Janeiro apresentadas neste trabalho. Os demais são discutidos em maior detalhe em trabalhos anteriores (BRITO, 2007; BRITO; CAVENAGHI; JANNUZZI, 2008).

\section{Precisão}

O critério de precisão refere-se ao erro encontrado quando os resultados são comparados com os dados observados. A análise destes erros servirá para apontar o método de projeção populacional mais adequado - para um determinado local ou propósito - para melhor atender às necessidades da população. Sabe-se que sempre existirá erro de precisão, mas busca-se que este seja o menor possível.

O erro de precisão $(E)$ pode ser definido como a diferença entre a população projetada $(P)$ e a população observada $(O)$, para um mesmo domínio e ano:

$$
E_{t}=P_{t}-O_{t} \text {, onde } t=\text { ano. }
$$

Normalmente, os erros de precisão são expressos em termos percentuais. $\mathrm{O}$ erro percentual (EP) é o erro de precisão em relação à população observada, expresso em porcentagem:

$$
E P_{t}=\left[\frac{P_{t}-O_{t}}{O_{t}}\right] \times 100 \text {, onde } t=\text { ano. }
$$

Em breve revisão bibliográfica - nacional e internacional - sobre avaliação de projeções populacionais para pequenos domínios, verificou-se que o critério de precisão é o mais utilizado. Há algumas medidas de precisão disponíveis para este tipo de análise, entre as quais duas são utilizadas 
com maior frequência e consideradas tradicionais: a medida de erro médio percentual - EMP; e a medida de erro médio percentual em módulo - EMPM (JUDSON et al., 2004). A primeira se traduz na média de todos os erros percentuais e a única diferença em relação à segunda é que esta fornece o módulo dos erros percentuais. Resumindo, o EMP é uma medida de tendência média e pode ser usada como base para testar a presença de tendência média significante, enquanto o EMPM é uma medida de precisão que indica o quão "perto" as estimativas chegaram do valor observado, em média (DEVINE; COLEMAN, 2003).

$$
E M P_{t}=\frac{\sum_{i=1, n} E P_{i, t}}{n} \mathrm{e} E M P M_{t}=\frac{\sum_{i=1, n}\left|E P_{i, t}\right|}{n},
$$

onde: $n=$ número de domínios menores, $i$ $=1 . . n$ domínios e $t=$ anos.

Definir uma margem de erro aceitável não é uma tarefa clara e, às vezes, pode parecer subjetiva. No entanto, diversas características como tamanho da população, taxa de crescimento populacional, horizonte de projeção, entre outras, influenciam na definição de um percentual mínimo de erro. Conforme coloca Howe (2004), para uma pequena população (por exemplo, 2.000 habitantes), um erro de $5 \%$ pode ser aceitável, no entanto, se a população for maior (ex. 200.000), essa margem pode não ser aceitável. O horizonte de projeção também dificulta a definição de uma margem de erro aceitável, pois, à medida que o horizonte aumenta, o erro também cresce. Segundo Smith et al. (2001), para um horizonte de projeção de dez anos, o EMPM aceitável para pequenos domínios, como municípios, tem ficado entre $8 \%$ e $14 \%$.

No Brasil, os métodos de projeção populacional para pequenos domínios (municípios) considerados de boa precisão têm sido aqueles em que mais da metade dos municípios apresentam EP entre -10\% e 10\% (JARDIM, 1995; WALDVOGEL, 1997; WALDVOGEL; CAPASSI, 1998). Deve-se ressaltar que denominar municípios de pequenos domínios nem sempre corresponde à realidade, pois, no Brasil, o tamanho dos municípios varia enormemente. Assim, não basta definir a precisão somente em termos da divisão geográfica ou político-administrativa, mas também em comparação com o tamanho populacional e horizonte de projeção.

\section{Nível de detalhamento necessário}

De acordo com Smith et al. (2001), outro critério importante para avaliação de uma projeção - ou técnica - diz respeito ao nível de detalhamento geográfico, demográfico e temporal requerido por um usuário. Pensando no detalhe geográfico, observa-se que há maior oferta de projeções em níveis nacional e estadual, cuja elaboração normalmente faz parte da rotina dos países, tendo em vista que os limites geográficos para este nível de desagregação são estáveis e as informações estatísticas de melhor qualidade. Conforme aumenta o nível de desagregação, fica mais difícil estabelecer um limite geográfico (por exemplo, criação de novos municípios) e obter dados confiáveis.

No caso do detalhe demográfico, o potencial de variação é ilimitado. As projeções podem ser realizadas somente para população total ou desagregada por sexo, idade, cor, raça, etc., bem como para públicos-alvo (estudantes, força de trabalho, militares, pensionistas, entre outros). A variável idade, por exemplo, pode ser em idade simples ou em grupos quinquenais. Já o detalhe tempo$\mathrm{ral}$ se resume no horizonte de projeção e no intervalo entre as datas das projeções, que podem ser realizadas para $5,10,15$ ou 20 anos, com intervalos anuais, quinquenais, decenais. De todas as formas, o nível de detalhamento deve estar vinculado ao uso que se queira fazer das projeções e, portanto, deve-se adequar a este.

Todos os critérios definidos por Smith et al. (2001) têm sua importância na escolha das informações, técnicas e hipóteses que serão consideradas na construção de projeções ou para avaliação de projeções produzidas anteriormente. A importância relativa de cada critério irá variar de acordo com os objetivos do usuário. Acredita-se que todos os critérios devem ser regularmente avaliados pelas instituições e organizações voltadas para a tarefa cotidiana de realizar projeções.

Precisão e nível de detalhamento - critérios aqui enfocados - parecem constituir 
parâmetros de análise bastante relevantes no contexto nacional. Diversos programas públicos utilizam critérios per capita para repasses de verbas, sendo que muitos indicadores de resultados de ações governamentais - nas áreas da saúde e educação, por exemplo - dependem, no seu cômputo, de denominadores que são grupos populacionais específicos. Adicionalmente, apesar de ser tarefa rotineira, a avaliação das projeções torna-se ainda mais primordial quando nos afastamos da data de realização do último censo demográfico, que é a fonte mais confiável para estimativas com grande detalhamento geográfico.

\section{Técnicas de projeção de pequenos domínios}

Os métodos selecionados neste trabalho para avaliação dos seus resultados foram: AiBi; relação de coortes de Duchesne; e correlação de razões. Estes métodos estão descritos detalhadamente em outras partes, mas considerou-se importante listar aqui as principais características e dados necessários para sua aplicação. ${ }^{2}$ Os dados e as fontes utilizados neste trabalho, para aplicação de cada um dos métodos descritos a seguir, são detalhados em seção específica, após a descrição dos métodos e das estratégias adotados para avaliação dos resultados das projeções efetuadas.

\section{Método AiBi}

Originalmente chamado de Apportionment Method (WALDVOGEL, 1997; JARDIM, 2003; OLIVEIRA et al., 2004), este método foi aplicado pela primeira vez no Brasil por Madeira e Simões (1972). Atualmente, o $\mathrm{AiBi}$ é o método utilizado pelo IBGE para projetar a população total dos Estados e municípios brasileiros. Seu suposto básico é que as populações dos domínios menores constituem uma função linear da população do domínio maior. A desvantagem do método é que, por não existirem limites para as participações relativas, podem aparecer populações negativas (SANTOS, 1989). Para evitar esta desvantagem, é possível buscar alternativas como separar as áreas com taxas de crescimento positivas e negativas, como proposto por Frias (1987). De todo modo, não é recomendado utilizá-lo para projeções populacionais com horizontes muito extensos. Na verdade, o período utilizado para projeção exige informações de período do mesmo tamanho no passado. Em teoria, o método é recomendado para áreas menores que estejam em declínio populacional ou apresentem crescimento pequeno e, também, quando o padrão de crescimento populacional nas pequenas áreas é o mesmo da área maior. ${ }^{3}$ Seu cálculo pode ser visto a seguir:

$P_{t+10}=P_{t}+\frac{P_{t}-P_{t-10}}{P D M-P D M} *\left(P D M_{t+10}-P D M_{t}\right)$,

onde:

$\mathrm{P}=$ população do domínio menor;

PDM = população do domínio maior.

\section{Método relação de coortes de Duchesne}

Um dos procedimentos de adaptação do método das componentes que tem sido aplicado no Brasil é o método de relação de coortes proposto por Duchesne em 1987 (OLIVEIRA, 1996; IPARDES; IBGE; FNUAP, 2000; JARDIM, 2003). Os passos seguidos para projetar as populações dos domínios menores são os mesmos do método das componentes. A particularidade da proposta de Duchesne é a maneira de projetar as componentes, que, por serem domínios menores, exigem tratamento diferenciado. Então, a partir da projeção do domínio maior, são calculadas as taxas de crescimento de suas coortes, aplicando-se essa razão para cada coorte de idade do domínio menor, ajustada por um fator $K$, como apresentado a seguir:

\footnotetext{
2 Mais detalhes poderão ser examinados na bibliografia citada.

3 Para superar algumas limitações teóricas impostas pelo método, como o aparecimento de populações negativas, pode-se buscar algumas soluções intermediárias, como separar as áreas com crescimento daquelas com decréscimo populacional. No entanto, estes procedimentos são respostas empíricas e que dependem do contexto de aplicação.
} 
- computam-se as taxas de crescimento das coortes (CR) da população do domínio maior (PDM):

$$
{ }_{10} C R_{x}^{t, t+10}={ }_{10} P D M_{x+10}^{t+10} /{ }_{10} P D M_{x}^{t}
$$

- com base em Censos anteriores, computa-se o Índice de Diferencial de Crescimento por Coortes (K) da população do pequeno domínio (P) em relação à população do domínio maior (PDM):

$$
{ }_{10} K_{x}=\left({ }_{10} P_{x+10}^{t} /{ }_{10} P_{x}^{t-10}\right) /\left({ }_{10} P D M_{x+10}^{t} /{ }_{10} P D M_{x}^{t-10}\right)
$$

- para cada população do domínio menor $(P)$, aplica-se essa razão sobre a população da coorte anterior, multiplicada pelo fator $K$, diferencial para cada pequeno domínio:

$$
{ }_{10} P_{x+10}^{t+10}={ }_{10} K_{x} *_{10} C R_{x}^{t, t+10} *{ }_{10} P_{x}^{t}
$$

\section{Método correlação de razões}

Este método assume que a evolução da população está correlacionada com a variação de uma ou mais variáveis sintomáticas. A correlação é estimada por meio de um modelo de regressão, em que a variação se estabelece por meio do crescimento das variáveis em dois censos consecutivos. $\mathrm{O}$ modelo assume a seguinte forma:

$Y=a_{0}+a_{1} X_{1}+a_{2} X_{2}+\ldots+a_{n} X_{n}$, as coordenadas são:

$$
\begin{aligned}
Y_{h}= & \left(P_{h, t} / P_{T, t}\right) /\left(P_{h, 0} / P_{T, 0}\right) \\
X_{h}= & \left(S_{h, t} / S_{T, t}\right) /\left(S_{h, 0} / S_{T, 0}\right), \text { onde: } \\
P_{h, t}= & \text { população do domínio menor } h, \\
& \text { no ano } t ; \\
P_{T, t}= & \text { população total do domínio maior, } \\
& \text { no ano } t ; \\
P_{h, 0}= & \text { população do domínio menor } h, \\
& \text { no ano } 0 ; \\
P_{T, 0}= & \text { população total do domínio maior, } \\
& \text { no ano } 0 ; \\
S_{h, t}= & \text { variável sintomática do domínio } \\
& \text { menor } h, \text { no ano } t ; \\
S_{T, t}= & \text { variável sintomática do domínio } \\
& \text { maior, no ano } t ; \\
S_{h, 0}= & \text { variável sintomática menor } h, \text { no } \\
& \text { ano } 0 ; \\
S_{T, 0}= & \text { variável sintomática do domínio } \\
& \text { maior, no ano } 0 .
\end{aligned}
$$

A seleção das variáveis sintomáticas depende do contexto geográfico e da quali- dade das informações disponíveis. Em geral, dados sobre nascimentos, óbitos, matrículas escolares e número de eleitores são os mais naturais de se pensar. No entanto, o uso de variáveis sintomáticas pode variar muito e estará sempre vinculado à disponibilidade das informações em periodicidade curta e compatível com os períodos de projeção para todos os domínios. Além disso, seu uso dependerá também da criatividade do pesquisador em buscar informações, como, por exemplo, cadastros imobiliários, de empresas e de empregados ou profissionais de certas especialidades, para aplicações mais específicas.

Neste trabalho, serão utilizadas as duas medidas tradicionais de precisão para avaliação de projeções populacionais: a medida de erro médio percentual (EMP); e a medida de erro médio percentual em módulo (EMPM).

\section{Estratégia metodológica}

Para proceder à avaliação dos métodos, lançou-se mão do artifício de supor que os dados do Censo Demográfico de 2000 não existiam e que, portanto, não eram conhecidos nem o nível nem o padrão real das componentes demográficas na década anterior a 2000. Somente para o método de correlação de razões foram utilizados dados da década de 1990, incluindo a Contagem Populacional de 1996. Assim, foi necessário coletar informações anteriores a 2000 para que as estimativas e projeções populacionais fossem comparadas com os resultados do Censo Demográfico de 2000. Esta estratégia metodológica é válida a partir do suposto de que os dados do Censo Demográfico de 2000 são valores corretos da população residente nos municípios estudados, ou seja, não existe falha de cobertura no Censo. Adicionalmente, deve-se mencionar que esta estratégia metodológica adotada precisa ser tomada com muito cuidado, pois projetar as componentes demográficas para a década de 1990 e 2000 como se não as conhecêssemos requer bastante disciplina. Assim, procurou-se realizar estas projeções da forma mais isenta possível, para não 
provocar vieses nos resultados de nenhum dos métodos selecionados.

O primeiro passo para a realização da avaliação foi elaborar a projeção do total da população do Estado do Rio de Janeiro, estimada pelo método das componentes. ${ }^{4} \mathrm{De}$ acordo com a projeção realizada, em 2000 (com data de referência em 10 de julho), a população do Rio de Janeiro seria composta por 14.363.867 habitantes. Comparando-se a população projetada com aquela recenseada (retro-projetada para 10 de julho), verifica-se que a projeção é $0,09 \%$ inferior à população observada, o que significa um resultado bastante aproximado.

A projeção da população do Estado faz parte dos dados básicos essenciais para aplicação dos métodos selecionados para realizar as projeções dos municípios do Rio de Janeiro, mas, antes de realizar as projeções para os pequenos domínios, cabe mencionar outra estratégia metodológica necessária. Os municípios que se desmembraram de outro, ao longo dos anos, tiveram que ser reagrupados ao seu município de origem, para que, durante o processo de elaboração das projeções, as populações estivessem compatibilizadas em nível territorial. Assim, para fins de comparação, as populações municipais observadas no Censo Demográfico de 2000 também passaram pelo processo de reagrupamento. Ressaltase, como exemplo, um caso especial que ocorreu com o município de Macuco, já que este foi desmembrado de três outros municípios - Cantagalo, Cordeiro e São Sebastião do Alto. Dessa forma, foi necessário criar uma área mínima comparável (AMC), agrupando-se as populações dos quatro municípios, observadas no Censo de 2000, e agrupando-se as populações projetadas dos três municípios que deram origem a Macuco, os quais foram projetados separadamente, pois, até 1996, Macuco ainda não havia sido contemplado na Contagem Populacional de 1996. Com isso, o universo de projeção ficou reduzido a 60 municípios.

\section{Dados}

Na aplicação do método $\mathrm{AiBi}$, são necessários os dados de população total dos municípios do Rio de Janeiro em períodos anteriores. Foram utilizados os dados de 1980 e 1991, disponíveis nos Censos Demográficos destes anos.

Para o método relação de coortes de Duchesne, os dados básicos utilizados foram: populações municipais do Rio de Janeiro, por sexo e grupos etários, em 1980 e 1991; e projeção das componentes demográficas do Estado, também disponíveis nos Censos Demográficos de 1980 e 1991.

No método de correlação de razões, os dados básicos utilizados, segundo municípios do Rio de Janeiro, foram: nascidos vivos e óbitos ocorridos nos períodos 19891991 e 1994-1996, a partir das Estatísticas do Registro Civil, IBGE; matrículas do ensino fundamental, nos períodos 1989-1991 e 1994-1996, utilizando como fontes os dados do Censo Escolar e aqueles disponíveis na Fundação Cide; 5 número de eleitores, nos períodos 1989-1991 e 1994-1996, com dados do TRE do Estado do Rio de Janeiro; e população total em 1991 e em 1996, com dados do Censo Demográfico de 1991 e Contagem populacional de 1996.

\section{Avaliação dos resultados}

Analisando-se o EMP (Tabela 1), é possível verificar que as três projeções, em média, tendem a ficar subestimadas em relação à população observada. A projeção realizada pelo $\mathrm{AiBi}$ apresentou maior tendência a ficar subestimada $(-1,89 \%)$, seguida daquela elaborada pelo método de correlação de razões $(-1,21 \%)$, enquanto a projeção pelo método de relação de coortes mostrou leve tendência negativa de $-0,41 \%$. Considerando-se o nível de EMPM aceitável sugerido por Smith et al. (2001) - entre 8\% e $14 \%$, para projeção de municípios no horizonte de dez anos -, pode-se afirmar que

\footnotetext{
${ }^{4}$ Metodologia disponível em Oliveira el al. (2004).

5 Os dados foram obtidos no Banco de Dados Municipais, disponível em:<http://200.156.34.70/tabnet/deftohtm.exe?cide Populacao|Popser.def>. Acesso em: 10 de dezembro de 2006.
} 


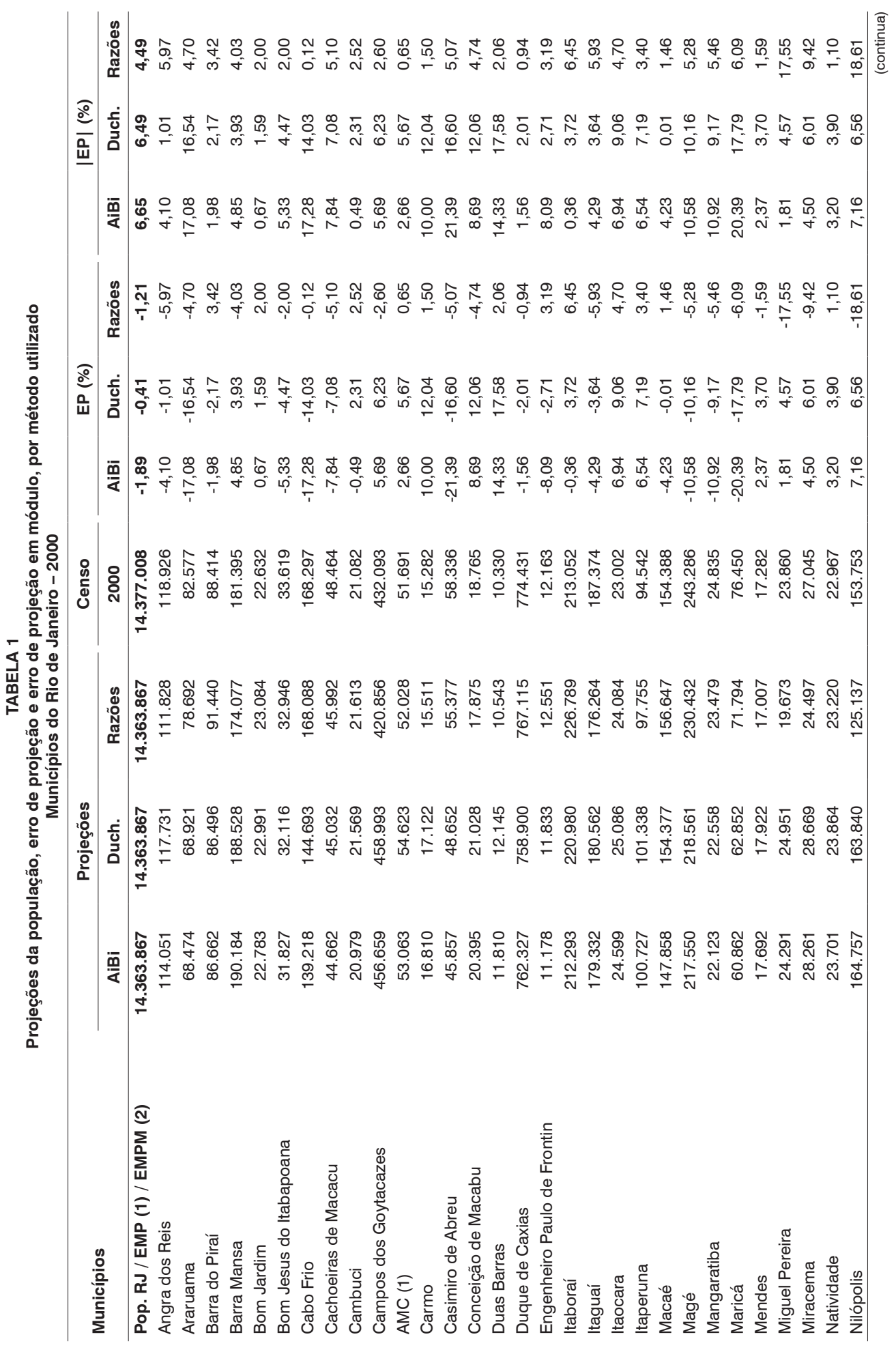




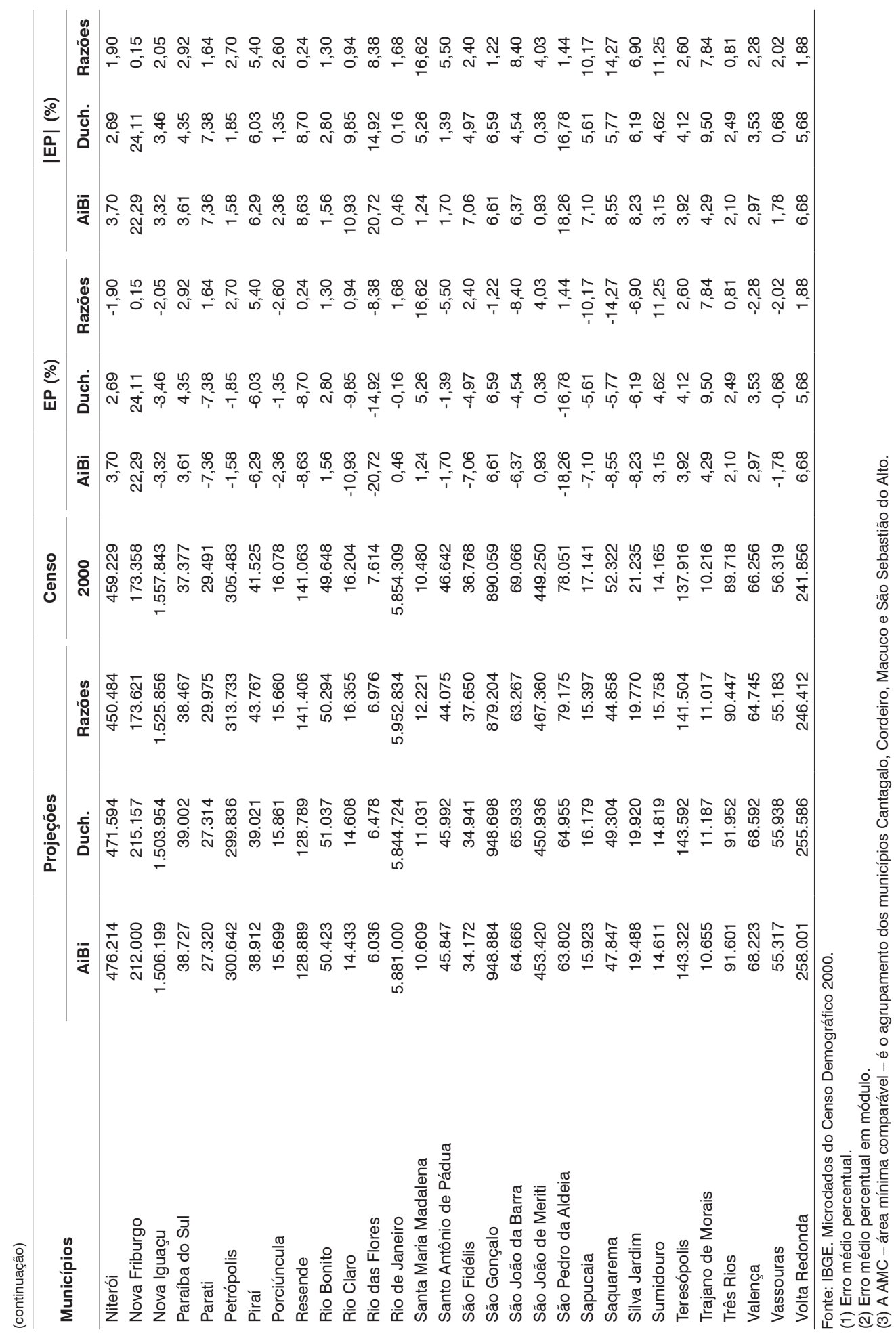


os três métodos apresentaram, em média, um bom nível de precisão. Os métodos $\mathrm{AiBi}$ e relação de coortes, em um horizonte de projeção de nove anos, registraram EMPMs de, respectivamente, 6,65\% e 6,49\%, enquanto para o de correlação de razões, em um horizonte de quatro anos, o EMPM foi de $4,49 \%$.

No Gráfico 1, observa-se a distribuição de municípios segundo os intervalos de erro de projeção para cada um dos três métodos aplicados. A maior proporção de municípios com os menores erros de projeção correspondeu ao método de correlação de razões, em que $92 \%$ dos municípios apresentaram EP entre $-10 \%$ e $10 \%$, sendo que em $73 \%$ o erro ficou entre $-5 \%$ e $5 \%$. Com a aplicação do método de relação de coortes, $83 \%$ dos municípios registraram EP entre -10\% e 10\% (52\% entre $-5 \%$ e $5 \%$ ). A distribuição do EP, quando aplicado o $\mathrm{AiBi}$, está bem próxima do método de relação de coortes - $82 \%$ dos municípios com erro entre -10\% e 10\% (52\% entre $-5 \%$ e $5 \%$ ).

O comportamento dos EMPMs, por tamanho populacional (Gráfico 2), mostra que, quanto maior o porte populacional do município, o EMPM tende a diminuir, o que pode ser observado na aplicação dos três métodos. Isso se deve, em primeiro lugar, ao fato de estarem sendo observadas no país, a cada novo levantamento censitário, taxas de crescimento populacional mais baixas em municípios maiores, fazendo com que a tendência inercial do passado se torne um elemento preditor importante. Nesses municípios, o crescimento vegetativo acaba tendo maior peso na determinação populacional, sendo menos sensíveis as flutuações conjunturais do movimento migratório, ao contrário das pequenas localidades.

Nos municípios com populações inferiores a 15.000 habitantes, a relação de coortes é o método que apresenta o maior EMPM. Em geral, o EMPM do método de correlação de razões se destaca como o menor, em comparação com os outros dois, já que é o único método que incorpora tendências - indiretas - de crescimento mais recentes.

Apesar de se verificar que o erro médio percentual em módulo diminui à medida que aumenta a população, a análise dos erros mínimos e máximos, também segundo o tamanho populacional (Gráfico 3), mostra que os maiores erros não estão nos menores municípios. Nos três métodos, os erros máximos aparecem no terceiro grupo de municípios (150.000 a 1.500.000 habitantes).

GRÁFICO 1

Distribuição da frequência dos erros de projeção da população, segundo métodos utilizados Municípios do Rio de Janeiro - 2000

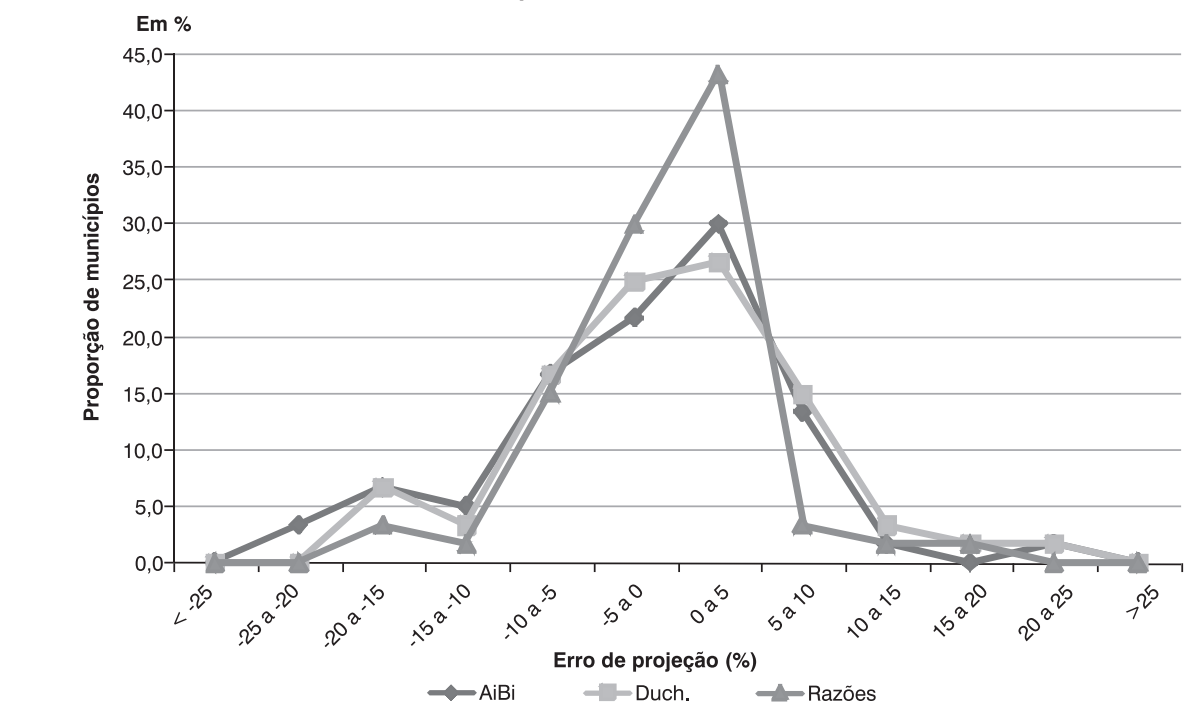

Fonte: IBGE. Microdados do Censo Demográfico 2000. 
GRÁFICO 2

Erro médio percentual em módulo (EMPM), por tamanho da população recenseada, segundo métodos utilizados Municípios do Rio de Janeiro - 2000

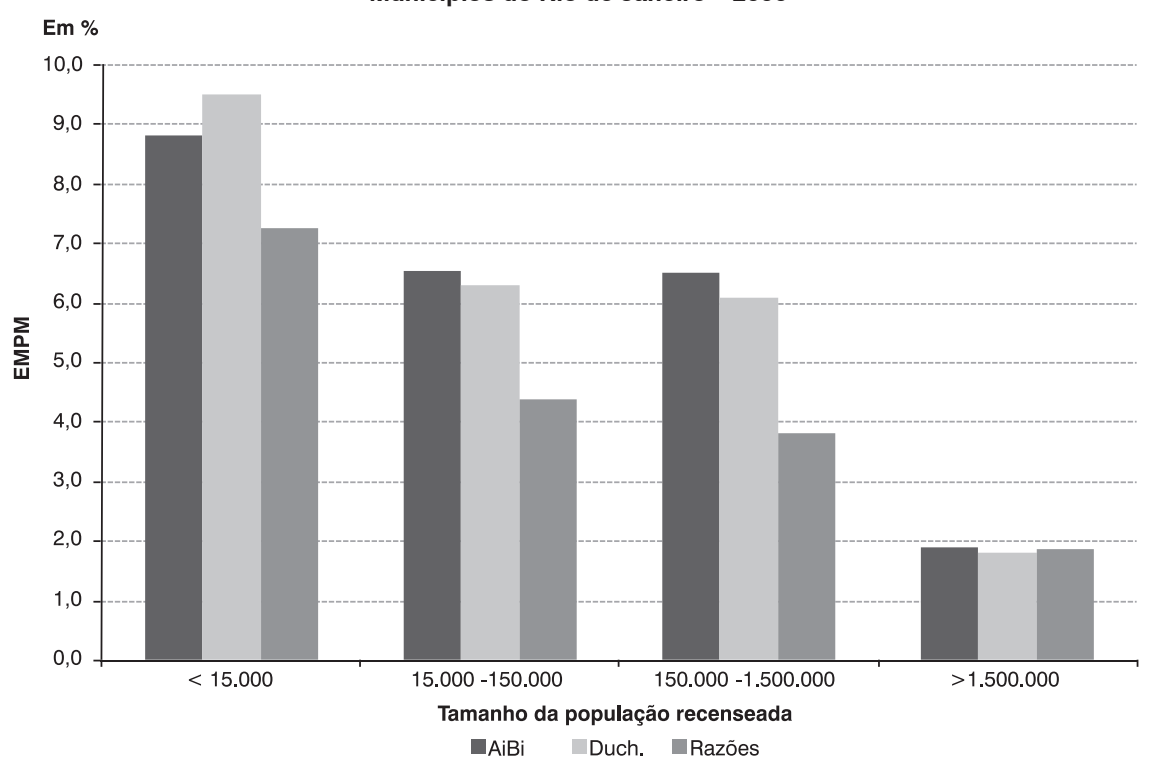

Fonte: IBGE. Microdados do Censo Demográfico 2000.

GRÁFICO 3

Erro máximo, erro médio e erro mínimo percentual em módulo versus população recenseada, segundo métodos utilizados

Municípios do Rio de Janeiro - 2000

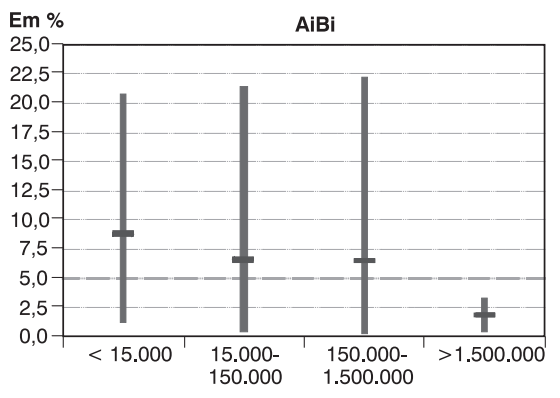

Tamanho da população recenseada

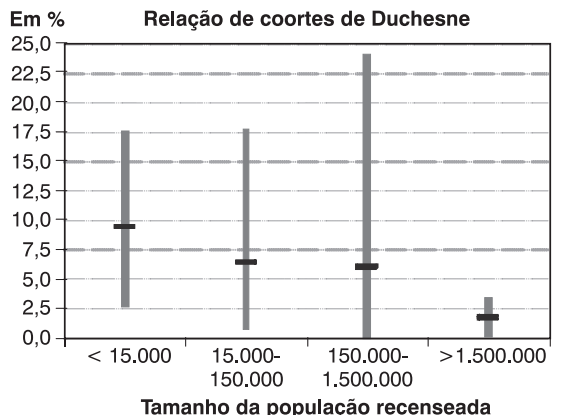

Tamanho da população recenseada

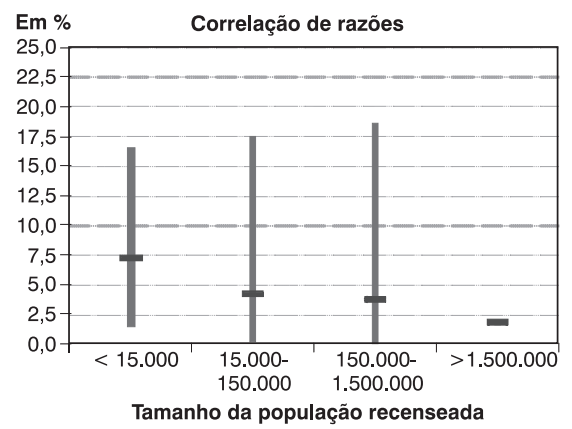

Fonte: IBGE. Microdados do Censo Demográfico 2000. 
Assim, deve-se atentar para o fato de que, em média, conforme se eleva o contingente populacional, decresce o erro de projeção, mas isso não quer dizer que os municípios maiores estejam isentos de grandes erros. Entre os três métodos, o menor e o maior EMPMs (praticamente zero e quase 25\%) foram encontrados na aplicação da relação de coortes. Logo, apesar de, em média, o método apresentar boa precisão, o planejamento de uma política pública para a população de um município cuja projeção difere em $25 \%$ da população observada mostra-se bastante problemático.

$\mathrm{Na}$ Tabela 2 há um resumo de algumas estatísticas descritivas referentes aos erros de projeção em módulo, segundo os três métodos. Observa-se que os métodos $\mathrm{AiBi}$ e relação de coortes de Duchesne apresentam comportamento parecido em termos de erro de projeção, mas este último com desempenho um pouco melhor. $\mathrm{Na}$ análise das estatísticas do EPM, o método de correlação de razões se destaca, apresentando, no geral, melhores resultados, o que pode ser justificado pelo fato de seu modelo estatístico incorporar informações novas e mais recentes em suas estimativas, apesar do sub-resgistro da contagem de 1996 (JARDIM, 2003). Já os métodos $A i B i$ e relação de coortes baseiam-se mais na tendência de crescimento da população, no entanto, o segundo tem como diferencial o fato de incorporar informação mais específica no cômputo das projeções: o comportamento das estruturas etárias (e não apenas a da população total, como no AiBi).

Analisando-se os Gráficos 4 e 5, verificase que as taxas médias anuais de crescimento geométrico da projeção de $2000(\mathrm{AiBi}$

TABELA 2

Estatísticas descritivas dos erros de projeção da população em módulo, segundo os métodos utilizados Municípios do Rio de Janeiro - 2000

\begin{tabular}{lccccc}
\hline Métodos & $\begin{array}{c}\text { Erro } \\
\text { médio }\end{array}$ & $\begin{array}{c}\text { Desvio } \\
\text { padrão }\end{array}$ & $\begin{array}{c}\text { Erro } \\
\text { mínimo }\end{array}$ & $\begin{array}{c}\text { Erro } \\
\text { máximo }\end{array}$ & $\begin{array}{c}\text { Coef. de } \\
\text { variação }\end{array}$ \\
\hline $\mathrm{AiBi}$ & 6,65 & 5,69 & 0,356 & 22,290 & 85,6 \\
Relação de coortes & 6,49 & 5,20 & 0,007 & 24,112 & 80,2 \\
Correlação de razões & 4,49 & 4,22 & 0,124 & 18,612 & 94,0 \\
\hline
\end{tabular}

Fonte: IBGE. Microdados do Censo Demográfico 2000.

\section{GRÁFICO 4}

Taxa média anual de crescimento geométrico - Censos (91/80) e projeção AiBi versus Censo (00/91) Municípios do Rio de Janeiro

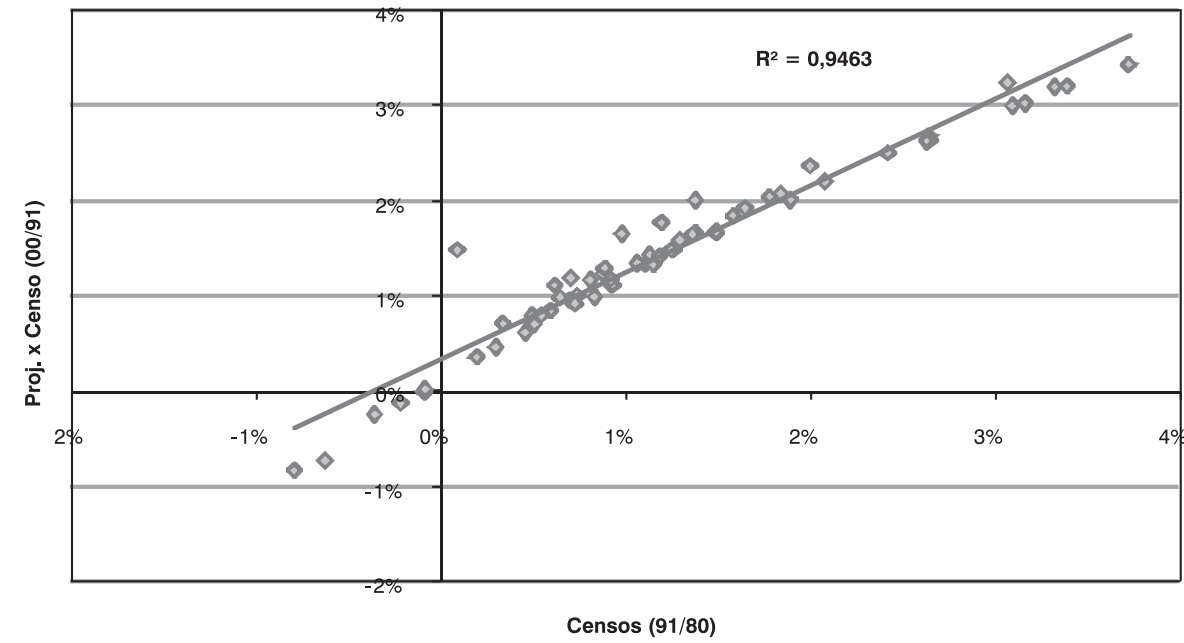

Fonte: IBGE. Microdados do Censo Demográfico 2000. Censo de 1991 e Contagem de 1996. 


\section{GRÁFICO 5}

Taxa média anual de crescimento geométrico - Censos (91/80) e projeção relação de coortes versus Censo (00/91) Municípios do Rio de Janeiro

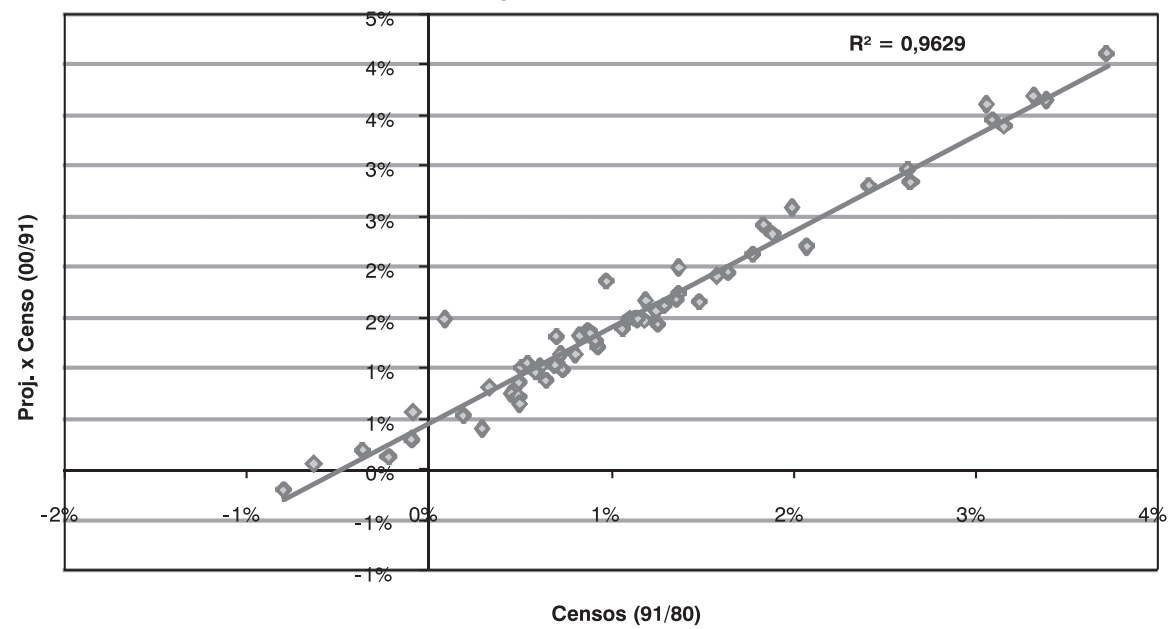

Fonte: IBGE. Microdados do Censo Demográfico 2000. Censo de 1991 e Contagem de 1996.

GRÁFICO 6

Taxa média anual de crescimento geométrico - Censos (91/80) e projeção correlação de razões versus Censo (00/91) Municípios do Rio de Janeiro

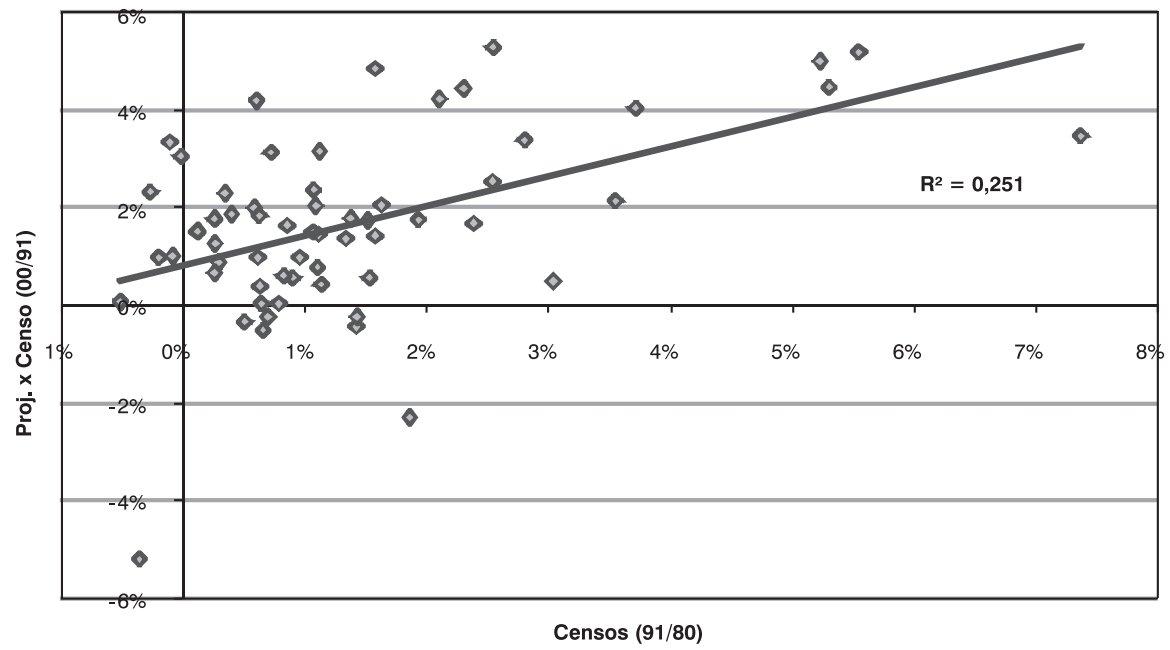

Fonte: IBGE. Microdados do Censo Demográfico 2000. Censo de 1991 e Contagem de 1996.

e rel. de coortes, respectivamente) versus Censo 1991, em comparação com o Censo 1991 versus 1980, são altamente correlacionadas. Em contrapartida, fazendo-se a mesma comparação com base no método de correlação de razões, tem-se uma cor- relação em torno de $25 \%$ (Gráfico 6). Isto ocorre porque o método, além da tendência de crescimento populacional, incorpora a tendência de outras variáveis demográficas.

É importante comentarmos que estudos voltados para avaliar a precisão de 
projeções populacionais (HOWE, 2004; SMITH et al., 2001; JARDIM, 1995) também correlacionam o erro de projeção ao grau de crescimento/decréscimo de uma população. Segundo Howe (2004, p. 14, tradução nossa), "Populações com crescimento moderado são estimadas com maior precisão do que populações que estão crescendo ou decrescendo rapidamente". De fato, nos Gráficos 7 e 8 referentes aos métodos

GRÁFICO 7

Erros de projeção em módulo em 2000, segundo taxas médias anuais de crescimento geométrico - Censos $(91 / 80)$ - método AiBi

Municípios do Rio de Janeiro

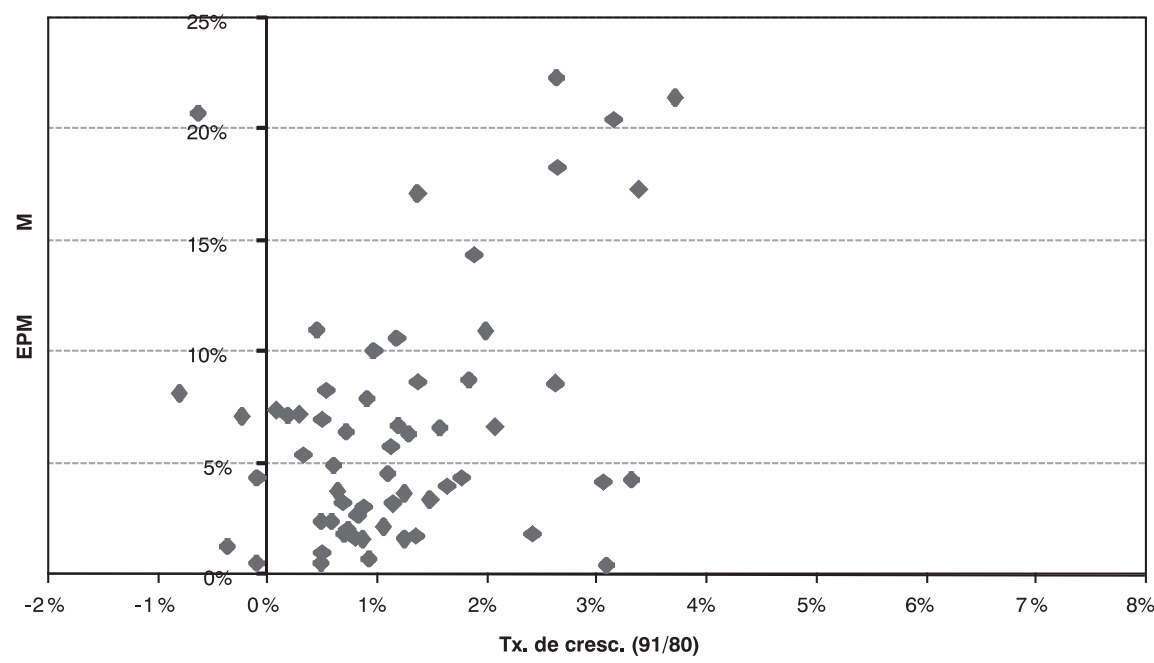

Fonte: IBGE. Microdados do Censo Demográfico 2000. Censo de 1991 e Contagem de 1996.

GRÁFICO 8

Erros de projeção em módulo em 2000, segundo taxas médias anuais de crescimento geométrico - Censos $(91 / 80)$ - relação de coortes

Municípios do Rio de Janeiro

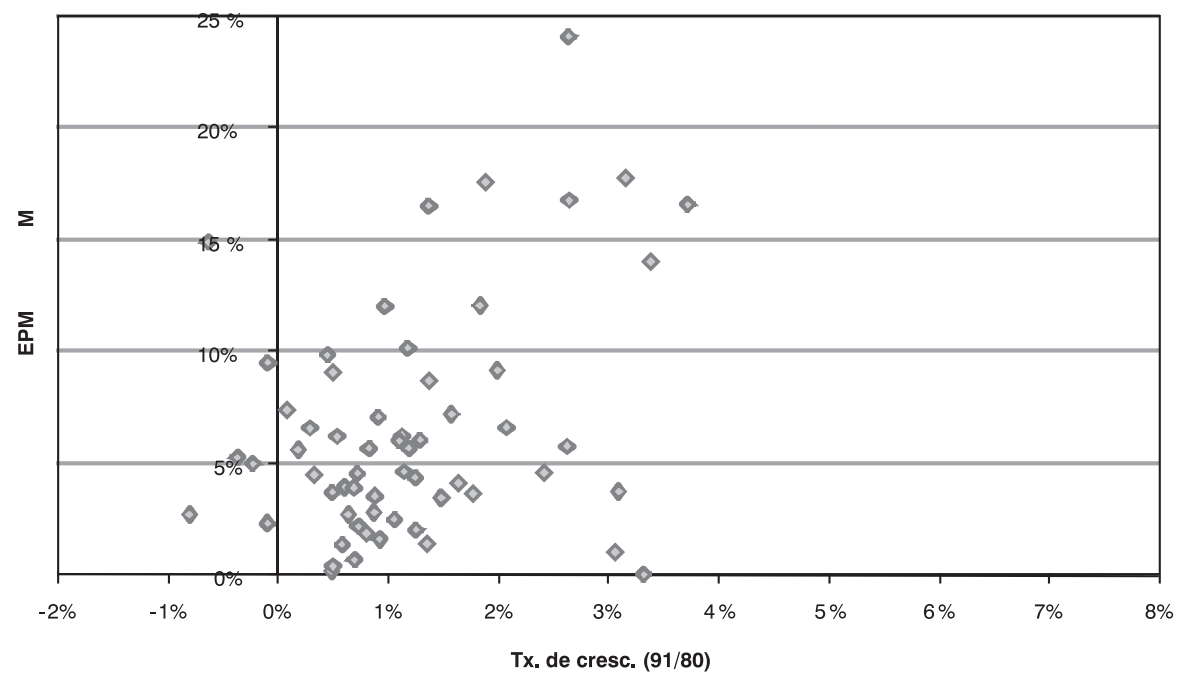

Fonte: IBGE. Microdados do Censo Demográfico 2000. Censo de 1991 e Contagem de 1996. 
AiBi e relação de coortes, respectivamente, verifica-se uma concentração de erros de projeção absolutos inferiores a $10 \%$ no intervalo de taxa média anual de crescimento geométrico entre $-1 \%$ e $2 \%$.

No método de correlação de razões, apesar de não ser tão correlacionado com a tendência de crescimento, menores erros em módulo também tenderam a se concentrar nos intervalos de crescimento/ decréscimo mais moderados (Gráfico 9).

Cabe ressaltar que, conforme ocorreu na relação do erro de projeção com o tamanho populacional, para taxas de crescimento moderadas também aparecem grandes erros. Segundo Jardim (1995), em 1978, alguns autores fizeram uma estratificação de municípios em níveis de taxas de crescimento na busca por melhores resultados de projeções populacionais para pequenos domínios. No entanto, na opinião da autora, seria mais adequada uma estratificação por tamanho de município. Jardim (1995, p. 47) argumenta que "a troca de classe de estratificação de um município de uma década para outra é menos provável de ocorrer do que a mudança do seu ritmo de crescimento".

A estratificação em níveis de taxas de crescimento ou por tamanho populacional pode ser uma ferramenta a mais para melhorar as estimativas e projeções populacionais para pequenos domínios. Mas, como visto na análise dos resultados do Rio de Janeiro, tanto em municípios com maiores populações quanto naqueles com taxas de crescimento moderadas identificaram-se grandes erros. Deve-se pensar no sentido de que esses casos podem ser tratados, pois todos os municípios, sem exceção, necessitam de projeções adequadas para seus planejamentos.

A análise dos EMPMs segundo as Regiões de Governo estabelecidas pela Fundação Cide (2007) revela que a das Baixadas Litorâneas destacou-se com os maiores erros médios em módulo (Gráfico 10). Quando aplicado o método de correlação de razões, os erros médios nesta região são bem menos expressivos, provavelmente pela incorporação de informações adicionais. Os maiores erros (acima de 10\%, em módulo) estão concentrados nesta região quando aplicados os métodos AiBi e relação de coortes. A análise dos erros de projeção mostrou que, nos municípios da Região das Baixadas Litorâneas, as projeções com os maiores erros ficaram subestimadas, sinal de que não foi captada a entrada de população nessas áreas.

GRÁFICO 9

Erros de projeção em módulo em 2000, segundo taxas médias anuais de crescimento geométrico - Censos $(91 / 80)$ - correlação de razões Municípios do Rio de Janeiro

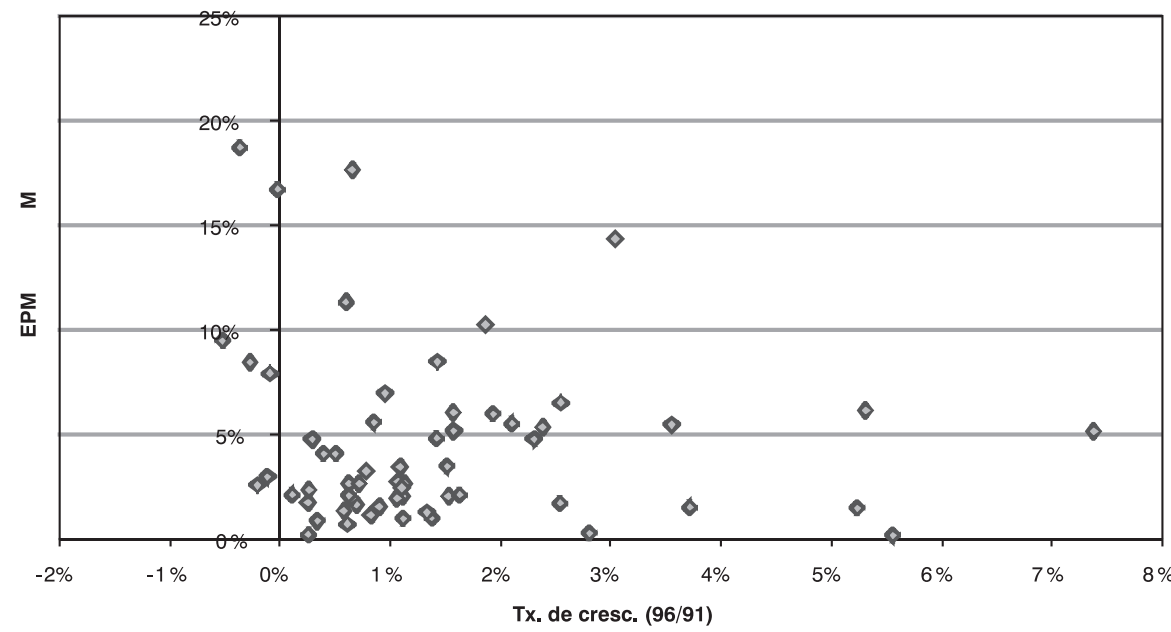

Fonte: IBGE. Microdados do Censo Demográfico 2000. Censo de 1991 e Contagem de 1996. 


\section{GRÁFICO 10}

Erro médio percentual em módulo (EMPM), segundo métodos utilizados Regiões de Governo do Rio de Janeiro - 2000

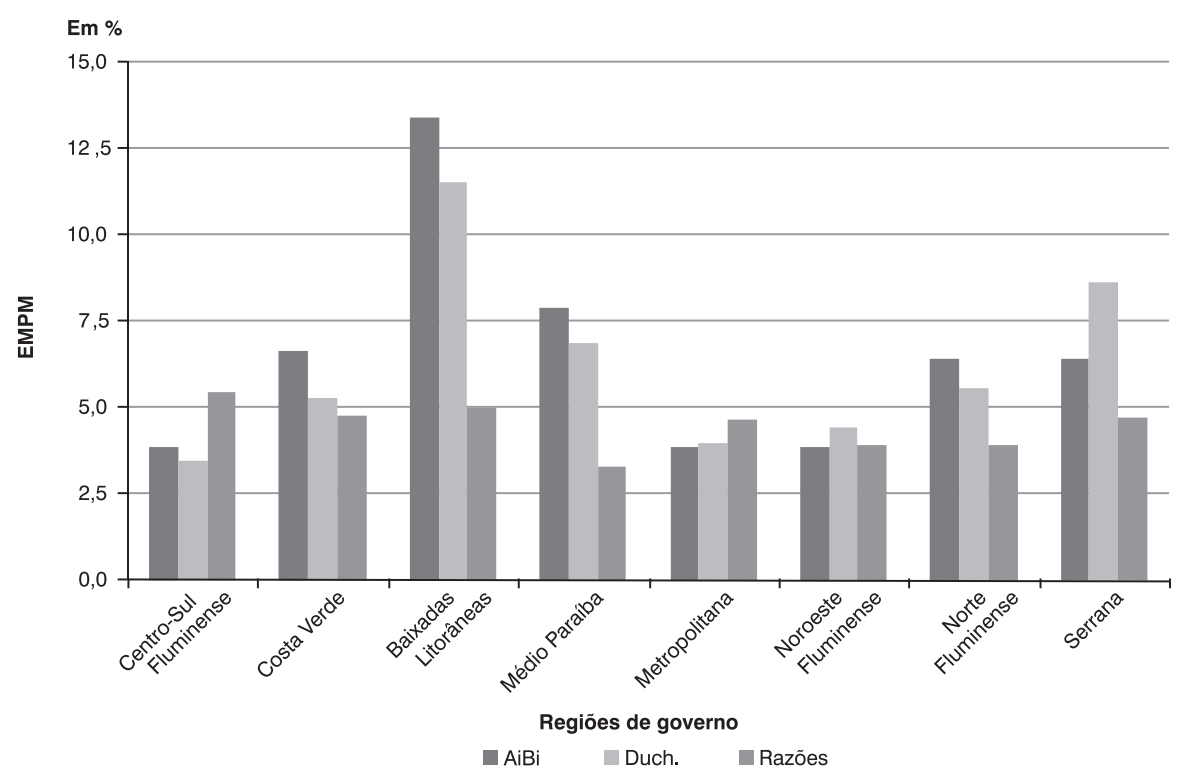

Fonte: IBGE. Microdados do Censo Demográfico 2000; Fundação Cide.

Na Tabela 3, nota-se que o erro na Região das Baixadas Litorâneas está relacionado, certamente, ao forte crescimento da população dessa área nos anos 1990, em relação à década anterior.

Conforme analisado, diversos fatores influenciam a produção das projeções populacionais para pequenos domínios: o tamanho do universo de projeção; a inten- sidade das taxas de crescimento; e a homogeneidade das regiões. Estas análises podem ajudar a pensar em alternativas para melhorar a precisão das projeções populacionais para estes domínios menores, com base nos métodos disponíveis, a partir de adaptações que considerem as heterogeneidades presentes nos locais de estudo.

TABELA 3

Taxas de crescimento demográfico

Regióes de Governo do Rio de Janeiro - 1970-2000

Em porcentagem

\begin{tabular}{lccc}
\hline Região do Governo & $\mathbf{1 9 8 0 / 1 9 7 0}$ & $\mathbf{1 9 9 1 / 1 9 8 0}$ & $\mathbf{2 0 0 0 / 1 9 9 1}$ \\
\hline Estado do Rio Janeiro & 2,30 & 1,15 & 1,30 \\
Região Metropolitana & 2,44 & 1,03 & 1,17 \\
Região Noroeste Fluminense & $-0,12$ & 1,08 & 0,97 \\
Região Norte Fluminense & 0,89 & 1,58 & 1,47 \\
Região Serrana & 2,18 & 1,56 & 1,01 \\
Região das Baixadas Litorâneas & 2,36 & 2,36 & 4,13 \\
Região do Médio Paraíba & 2,99 & 1,34 & 1,38 \\
Região Centro-Sul Fluminense & 1,33 & 1,09 & 1,22 \\
Região da Baía da llha Grande & 3,39 & 3,08 & 3,47 \\
\hline
\end{tabular}

Fonte: IBGE. Censos Demográficos IBGE; Fundação Cide. Anuário Estatístico do Estado do Rio de Janeiro. 
Finalmente, além da comparação com os resultados do Censo Demográfico de 2000 , tendo em vista que em $1 \stackrel{0}{\text { de abril de }}$ 2007 foi realizada contagem da população para os municípios brasileiros com até 170.000 habitantes e mais 21 municípios selecionados acima dessa faixa de população (IBGE, 2007a), pode-se comparar os resultados para os municípios onde ocorreu a contagem populacional. Com esta seleção, dos 92 municípios do Estado do Rio de Janeiro, 15 ficaram de fora desta comparação. Com a mesma metodologia aplicada para os dados de 2000 , foi realizada uma comparação de projeções populacionais para $2007 \mathrm{com}$ a contagem, sendo possível calcular os erros de projeção para 47 municípios.

Os resultados comparados com a contagem são menos satisfatórios do que os anteriores (Tabela 4). No entanto, é preciso considerar que o horizonte de projeção nos métodos $\mathrm{AiBi}$ e relação de coortes para esta comparação é de 16 anos e no de correlação de razões é de 11 anos. Por isso, não é surpresa que novamente este último método apresente estimativas com o menor EMPM (abaixo de 13\%, enquanto os demais registraram acima de 15\%). Cabe ressaltar, ainda, que não foi retirado o erro de projeção do domínio maior, que certamente reduziria o EMPM.

$\mathrm{Na}$ aplicação dos métodos de correlação de razões e $\mathrm{AiBi}$, respectivamente, $49 \%$ e $43 \%$ dos municípios apresentaram erro percentual entre $-10 \%$ e $10 \%$. Já para as projeções do método de relação de coortes, esta proporção não chegou a $40 \%$. Porém, novamente, deve-se lembrar que o tamanho do universo de projeção ficou reduzido, pois somente foram selecionados municípios com menos de 170.000 habitantes.

A tendência no comportamento geral das projeções mudou totalmente de direção e se mostrou bem mais intensa. Nos três casos, as projeções tendem a superestimar a população recenseada na Contagem Populacional de 2007. A tendência mais forte aparece na aplicação do método de relação de coortes, com EMP de 11,7\%. Mesmo levando-se em consideração que o período de projeção não é adequado para dois dos métodos avaliados, esta forte tendência de superestimação das projeções pode estar indicando que, na verdade, a Contagem Populacional de 2007 subestimou a população nos municípios aqui analisados. Deve-se lembrar que, no início da estratégia metodológica, assumiu-se que a população censitária de 2000 era correta, para estimar os erros de projeção. No caso da contagem, é necessário fazer a mesma suposição. No entanto, existem alguns indícios de que ou a população contada está subestimada, ou há outros erros de projeção para a população que não foi contada neste processo (municípios com mais de 170 mil habitantes, o que representa algo em torno de metade da população brasileira). Afinal, a projeção oficial do IBGE, então vigente, apontava para um total ao redor de 186 milhões de pessoas; já as estimativas - obtidas pela contagem e a projeção da parte não contada - estaria próxima de 183 milhões de pessoas.

\section{Considerações finais}

Tomando-se como base os critérios sugeridos em estudos referentes à avaliação de projeções populacionais para pequenos domínios, em média, os três métodos apresentaram um bom desempenho na projeção das populações totais dos municípios do Rio de Janeiro e, também em média, as projeções tenderam a ficar subestimadas, quando comparadas com a população do Censo Demográfico de 2000. Entretanto, dado o período selecionado para comparação dos resultados, o método que apresentou melhor desempenho, entre os três, foi o de correlação de razões. Conforme comentado na seção anterior, uma justificativa para seu melhor desempenho seria o fato de incorporar informações novas - não se baseando somente na tendência de crescimento - e mais recentes - apesar de supostamente não ser indicado o uso da contagem populacional, em função do sub-registro (JARDIM, 2003). O modelo estatístico de regressão ajustado apresentou resultados razoáveis considerando-se somente a correlação das estimativas populacionais com as variáveis sintomáticas utilizadas. Seria interessante o desenvolvimento de um modelo estatisticamente mais consistente, com base na análise de outras 


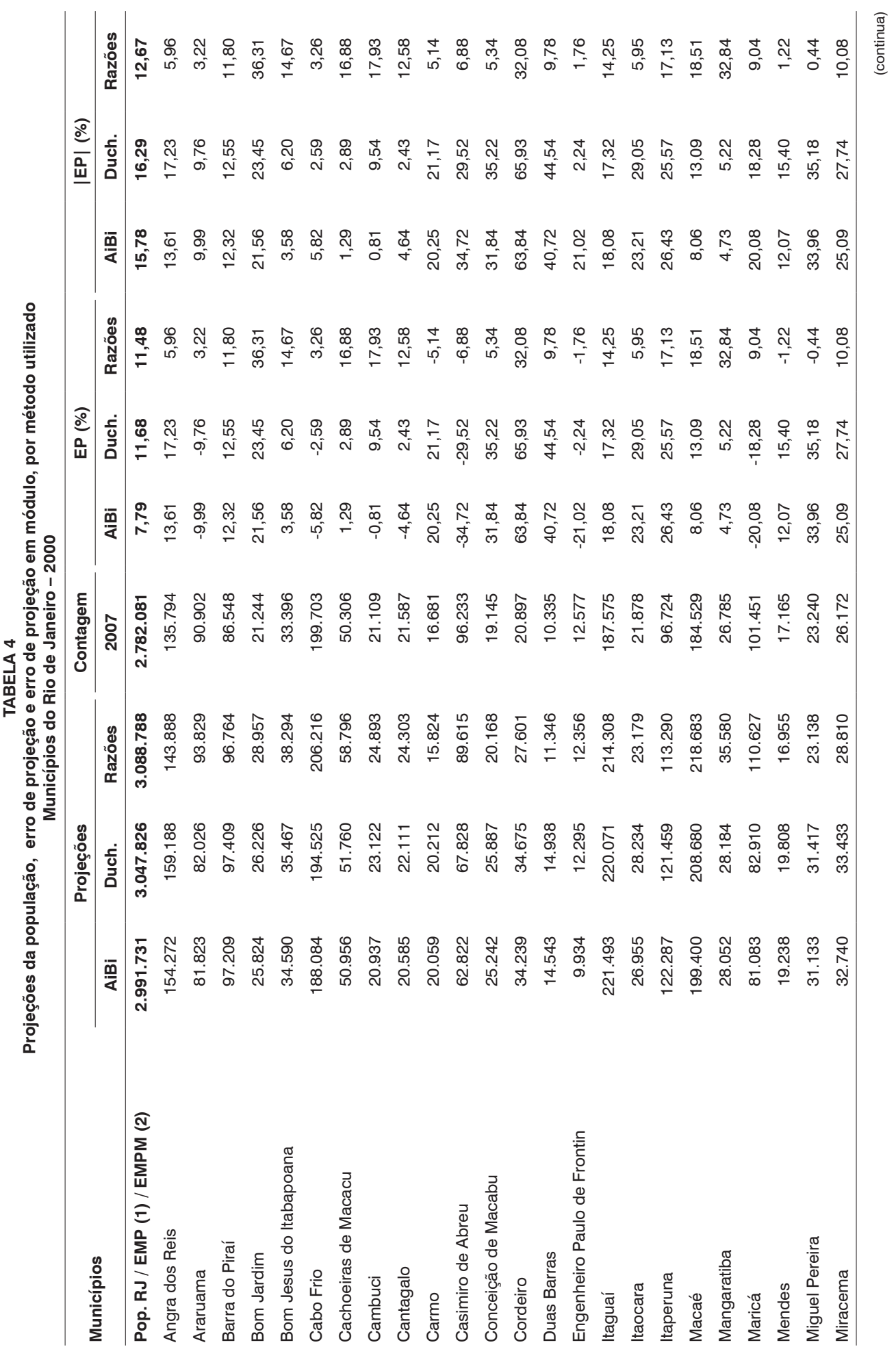




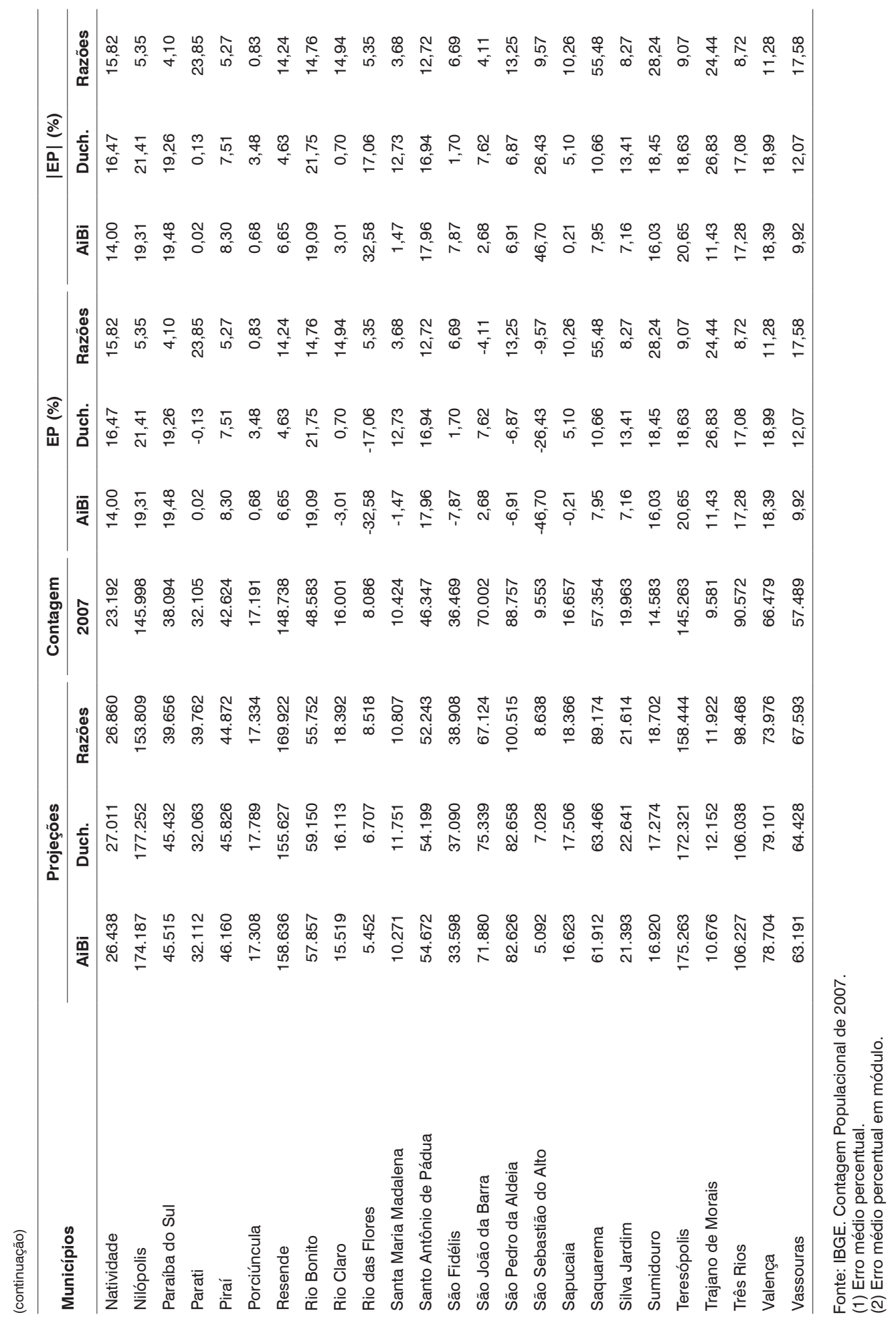


ferramentas estatísticas que devem ser utilizadas no processo de elaboração de um modelo de regressão. A inclusão de novas variáveis que possam estar correlacionadas com o crescimento populacional - inclusive o uso de varáveis econômicas - pode melhorar o desempenho do modelo.

Entretanto, para inserção de novas variáveis, necessita-se de um esforço das agências estatísticas em disponibilizar informações mais detalhadas em escala geográfica, mantendo-as periodicamente atualizadas, com séries mais longas e de fácil acesso. De acordo com Jannuzzi e Gracioso (2002), as agências estaduais vêm passando por uma grande mudança em termos de disseminação de informação estatística, em função das demandas da sociedade, das necessidades de informação para o planejamento público e das facilidades que as novas tecnologias de informação estão criando. Isto certamente contribuirá para melhores resultados da aplicação de métodos que utilizam variáveis sintomáticas.

A questão dos erros de projeção é de extrema importância, uma vez que as projeções populacionais vêm sendo utilizadas como subsídio de planejamentos e investimentos. No Brasil, o critério para boa precisão dos resultados do método de projeção populacional para domínios menores é quando grande parte dos erros encontrase em um intervalo entre $-10 \%$ e $10 \%$. Em alguns casos, o método aplicado gerou erro superior a $20 \%$, que seria inaceitável para qualquer tipo de planejamento. O ideal seria que os erros de projeção não fossem superiores a 5\%, em módulo. Deve-se buscar uma alternativa para que estes erros mais discrepantes sejam reduzidos. Jardim (1995) sugeriu uma estratificação por tamanho populacional ou de acordo com a taxa de crescimento, como colocado por outros autores. Adicionalmente, sugerimos que talvez fosse adequado estratificar os domínios menores segundo sua homogeneidade, baseandose em similaridades econômicas e sociais. Sabendo-se que a migração é a componente que mais afeta estes domínios, ao se agru- parem municípios com atratividades migratórias similares, é bem provável que se capte essa parcela da população que está sendo sub ou superestimada demasiadamente. Por exemplo, verificou-se que as populações de alguns municípios pertencentes à Região das Baixadas Litorâneas tenderam a ficar subestimadas. Diante dessas observações, fica a sugestão de uma estratificação dos municípios do Rio de Janeiro, segundo as Regiões de Governo, para então compor o total populacional do Estado. A distribuição da população de um domínio maior, como Estado, para domínios menores, como municípios, que notavelmente são heterogêneos, pode estar gerando esses diferenciais mais expressivos.

Em relação à comparação com a contagem populacional de 2007, observou-se que as projeções populacionais ficaram com forte tendência de superestimação, a partir dos três métodos aplicados, indicando uma possível subestimação da contagem. Também as estimativas realizadas pelo IBGE, para o Tribunal de Contas da União (TCU), apresentaram tendência de superestimação, com EMPM de $5,4 \%$, considerando os 77 municípios do Rio de Janeiro que tiveram contagem em 2007. 6

É importante lembrar que, conforme explicitado na apresentação dos resultados, a contagem populacional de 2007 só foi realizada para os municípios brasileiros com até 170.000 habitantes e mais 21 municípios selecionados acima dessa faixa de população (IBGE, 2007b). Para os 128 municípios restantes e o Distrito Federal, as populações foram estimadas. Dessa forma, a utilização da Contagem Populacional de 2007 não se torna adequada para realização de projeções populacionais, tendo em vista que podem ser identificados dois tipos de erro: o da contagem e o das estimativas. Para projeções com base em informações mais atualizadas, que não as do Censo de 2000, seria mais recomendado aguardar a divulgação das informações do Censo Demográfico de 2010.

Todavia, no modelo atual de censo decenal, ressalta-se a importância de reali-

\footnotetext{
${ }^{6}$ Disponível em: <http://tabnet.datasus.gov.br/cgi/tabcgi.exe?ibge/cnv/poptrj.def>. Acesso em: 18 nov. 2007.
} 
zação de contagem populacional no meio da década, assim como colocado por outros autores. Jardim (2003) destaca que a contagem populacional é uma ferramenta muito importante para os Estados conhecerem a atual situação dos municípios criados na década, dado que as leis de criação não informam corretamente os dados populacionais dos novos municípios, com a discriminação da cota retirada dos antigos. No Rio Grande do Sul, por exemplo, historicamente existe uma grande quantidade de novos municípios criados a cada década.

Por fim, esse trabalho mostrou a importância de utilização das diferentes metodolo-

\section{Referências}

BRITO, L. P. G. Avaliação da precisão de estimativas e projeções populacionais para pequenos domínios: Rio de Janeiro, 2000 e 2007. Dissertação (Mestrado). Rio de Janeiro: Ence/IBGE, 2007.

BRITO, L. P. G.; CAVENAGHI, S.; JANNUZZI, P. Avaliação da precisão de estimativas e projeções populacionais para pequenos domínios: Rio de Janeiro, 2000 e 2007. In: XI ENCONTRO NACIONAL DE ESTUDOS POPULACIONAIS. Anais... Belo Horizonte: Abep, 2008.

DEVINE, J.; COLEMAN, C. People might move but housing units don't: an evaluation of the state and county housing unit estimates. Washington: Population Division Working Paper Series no 71 - U.S. Census Bureau, 2003.

FRIAS, L. A. de M. Projeções da população residente e do número de domicílios particulares ocupados por situação urbana e rural, segundo as unidades da Federação no período 1985-2020 In: WONG, L. R.; HAKKERT, R.; LIMA, R. (Orgs.). Futuro da população brasileira: projeções, previsões e técnicas. Embu, São Paulo: Abep, 1987, p148-172.

FUNDAÇÃO CIDE. O Diário: vocações regionais para desenvolver. Disponível em: $<$ http://www.cide.rj.gov.br/noticias_eventos. php?cod_noticia $=28>$. Acesso em: 24 nov. 2007. gias para projeção populacional. Ao permitir a incorporação de tendências indiretas mais recentes de crescimento populacional - por meio das variáveis sintomáticas -, o método de correlação de razões se revelou, no caso do Estado do Rio de Janeiro, como mais preciso do que o $\mathrm{AiBi}$ e o de relação de coortes. Em situações em que os registros administrativos não gozam de boa cobertura e qualidade, a situação pode ser diferente. Por essa razão, para desenvolver o campo de estudos de projeções populacionais para pequenos domínios no Brasil, são necessários, ainda, vários outros estudos comparativos como o aqui apresentado.

HOWE, A. Assessing the accuracy of Australia's small area population estimates. Caberra: Australian Population Association APA, 12th Biennial Conference, 2004.

IBGE. Contagem da população 2007. Rio de Janeiro, 2007a. Disponível em: < http://www. ibge.gov.br/home/estatistica/populacao/ contagem2007/default.shtm>. Acesso em: 07 nov. 2007.

Metodologia das estimativas das populações de 128 municípios e Distrito Federal para 2007. Rio de Janeiro, 2007b. Disponível em: <http://www.ibge.gov.br/ home/estatistica/populacao/contagem2007/ metodologia_estimativas.pdf $>$. Acesso em: 25 out. 2007.

IPARDES; IBGE; FNUAP. Paraná: projeções das populações municipais por sexo e idade 2000 a 2010. Curitiba: Ence/IBGE/Ford Foundation, 2000.

JANNUZZI, P.; GRACIOSO, L. Produção e disseminação da informação estatística: agências estaduais no Brasil. São Paulo em Perspectiva, v.16, n. 3, jul./set. 2002.

JANNUZZI, P. Cenários futuros e projeções populacionais para pequenas áreas: método e aplicação para distritos paulistanos 20002010. Revista Brasileira de Estudos de População, v.24, n.1, p.109-136, jan./jun. 2007. 
JARDIM, M. L. Metodologia de estimativas e projeções populacionais para o Rio Grande do Sul e seus municípios. Porto Alegre: FEE, 2003.

. Utilização de variáveis sintomáticas para estimar a distribuição espacial de populações: aplicação aos municípios do Rio Grande do Sul. Belo Horizonte: UFMG/Cedeplar, 1995.

JUDSON, D.; POPOFF, C.; BATUTIS-JR., $M$. An evaluation of the accuracy of U.S. Census Bureau county population estimates. Statistics in Transition, v. 5, n. 2, p. 205235, 2004

MADEIRA, J. L.; SIMÕES, C. C. S. Estimativas preliminares da população urbana e rural, segundo as unidades da Federação, 1960/1980: por uma nova metodologia. Revista Brasileira de Estatística, v.33, n. 129, p.3-11, 1972.

NAÇÕES UNIDAS. Métodos para preparar projeções de população por sexo e idade - Manual III. Rio de Janeiro: IBGE, 1978.

OLIVEIRA, J.; ALBUQUERQUE, F. R.; LINS, I. Projeção da população do Brasil por sexo e idade para o período 1980-2050 - revisão 2004 - metodologia e resultados. Estimativas anuais e mensais da população do Brasil e das Unidades da Federação: 1980-2020 - metodologia. Estimativa das populações municipais - metodologia. Rio de Janeiro: IBGE, 2004.

OLIVEIRA, J.; FERNANDES, F. Metodologia e considerações acerca da projeção de população do Brasil: 1980-2020. São Paulo em Perspectiva, v.10, n. 2, abr./jun., p. 116123, 1996

PRESTON, S. H.; HEUVELINE, P.; GUILLOT, $M$. Demography: measuring and modeling population processes. Oxford: Blackwell, 2001, p. 168-175.

RAO, J. N. K. Small area estimation. Hoboken: Wiley, 2003.

SMITH, S.; TAYMAN, J.; SWANSON, D. State and local population projections: methodology and analysis. New York: Kluwer, capítulos 1, 2, 12 e 13, 2001.

SANTOS, T. F. Projeções da população de Pernambuco, desagregadas por microrregiões, até o ano 2010: aplicação de métodos alternativos. Dissertação (Mestrado). Recife: UFMG/Cedeplar, 1989.

SUPERINTENDÊNCIA DE ESTUDOS ECONÔMICOS E SOCIAIS DA BAHIA. Projeções de população por sexo e idade: Bahia, 1991-2020. Salvador: SEI, 1999.

WALDVOGEL, B.; CAPASSI, R. Projeção populacional como instrumento de planejamento regional: o caso do Estado de São Paulo. In: XI ENCONTRO NACIONAL DE ESTUDOS POPULACIONAIS. Anais... Belo Horizonte: Abep, 1998.

WALDVOGEL, B. Técnicas de projeção populacional para o planejamento regional. Belo Horizonte: UFMG/Cedeplar, 1997 (Estudos Cedeplar, 1).

\section{Resumen}

Estimaciones y proyecciones poblacionales para pequeños dominios: una evaluación de la precisión para municipios de Río de Janeiro en el año 2000 y 2007

Las proyecciones poblacionales se vienen utilizando, con una frecuencia cada vez mayor, como ayuda para planificar el desarrollo económico, social, político y ambiental de diverso países. Sin embargo, cuanto mayores son los niveles de detalle geográfico, demográfico y temporal requeridos, menos exactas son las proyecciones. En los pequeños dominios, como los municipios, por ejemplo, se enfrentan dificultades como el tamaño reducido de la población, la volatilidad de los datos en sus patrones de crecimiento, la falta de información de calidad, entre otros. El objetivo de este trabajo es evaluar algunas metodologías de proyecciones poblacionales para pequeños dominios, tomando como objeto de estudio a los municipios del 
Estado de Río de Janeiro. Las técnicas estudiadas son los métodos AiBi, relación de cohortes de Duchesne y correlación de razones, usadas para la comparación con los resultados del Censo 2000 y con el Recuento de 2007. Los resultados comparativos con el Censo 2000 indican que, en promedio, las estimaciones y proyecciones provenientes de la aplicación de los tres métodos presentan un nivel de precisión dentro de un margen aceptable, pero los errores varían de $-21,4 \%$ a $24,1 \%$ y las proyecciones tienden a ser subestimadas. La comparación de los resultados con el Recuento de 2007 se mostró menos exacta. Por los motivos descritos en este trabajo, el método de correlación de razones, que utiliza variables sintomáticas, mostró mejores resultados que el resto, dentro del conjunto de métodos evaluados para los municipios de Río de Janeiro.

Palabras-clave: Proyecciones poblacionales. Pequeños dominios. Estimaciones de precisión. Río de Janeiro.

\begin{abstract}
Demographic estimates and projections for small domains: an evaluation of the precision for the municipalities in the State of Rio de Janeiro in 2000 and 2007
\end{abstract}

Demographic projections have been used more and more frequently to generate information for planning economic, social, political and environmental development in many different countries. But the broader the levels of geographic, demographic and temporal details required, the less precise are the projections. In small domains, such as municipalities, difficulties come up that include small populations, volatility of the data on growth patterns, poor quality of information, and others. The objective of this article is to evaluate several different methodologies of demographic projections for small domains, taking the municipalities of the State of Rio de Janeiro (of which the City of Rio de Janeiro is the Capital), Brazil, as a set of examples. The techniques studied are the apportionment method (AiBi), Duchesne's relationship of cohorts and ratio correlations, used for comparisons with the results of the Federal Census of 2000 and with the Counting carried out in 2007. The comparative results with the Census of 2000 indicate that, on the average, the estimates and projections produced by applying the three methods show a precision level within acceptable margins, but the errors vary from $-21.4 \%$ to $24.1 \%$, and the projections tend to be underestimated. In contrast, the comparison of the results from the Counting of 2007 proved to be less precise. As described in this article, the method of ratio correlations, which uses symptomatic variables, was seen to be the best of the three methods used to evaluate the municipalities in the State of Rio de Janeiro.

Keywords: Demographic projections. Small domains. Precision estimates. Rio de Janeiro.

Recebido para publicação em 14/08/2009

Aceito para publicação em 05/02/2010 